NISTIR 7393

\title{
A Study of Metal Truss Plate Connectors When Exposed to Fire
}

Harman, K. A.

Lawson, J. R. 
NISTIR 7393

\section{A Study of Metal Truss Plate Connectors When Exposed to Fire}

Harman, K. A.

Lawson, J. R.

Fire Research Division

Building and Fire Research Laboratory

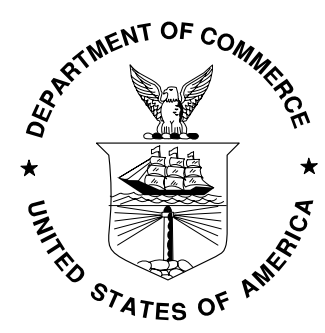

U.S. Department of Commerce Carlos M. Gutierrez, Secretary

Technology Administration Robert Cresanti, Under Secretary of Commerce for Technology

National Institute of Standards and Technology William Jeffrey, Director 


\section{TABLE OF CONTENTS}

LIST OF FIGURES $\ldots \ldots \ldots \ldots \ldots \ldots \ldots \ldots \ldots \ldots \ldots \ldots \ldots \ldots \ldots \ldots \ldots \ldots \ldots$

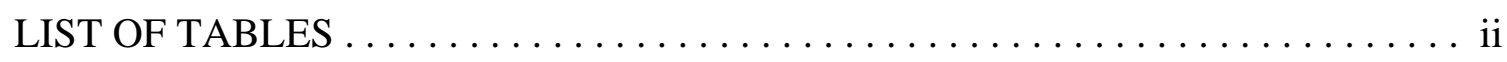

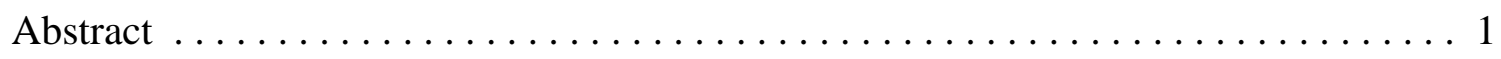

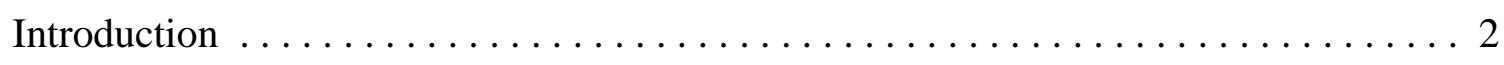

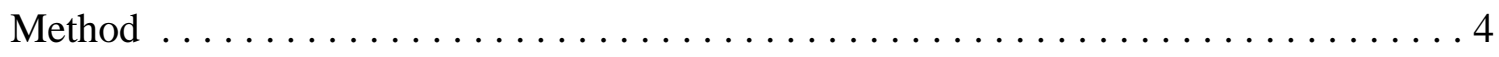

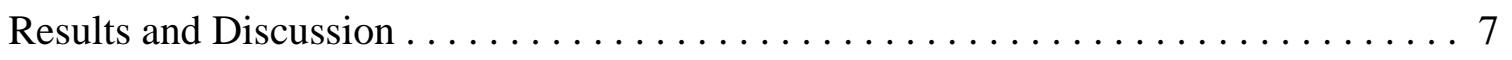

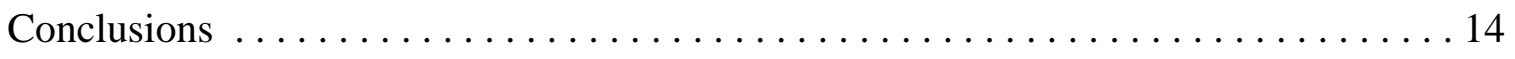

Acknowledgements . . . . . . . . . . . . . . . . . . . . . . 15

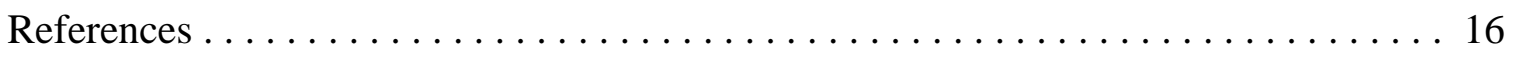




\section{LIST OF FIGURES}

Figure 1 Typical lightweight wood construction $\ldots \ldots \ldots \ldots \ldots \ldots \ldots \ldots \ldots$

Figure 2 Typical set up of test members $\ldots \ldots \ldots \ldots \ldots \ldots \ldots \ldots \ldots \ldots \ldots \ldots . \ldots$

Figure 3 Locations of thermocouples A, B, C, and D .............. 6

Figure 4 Close up of surface thermocouples $\mathrm{C}$ and $\mathrm{E} \ldots \ldots \ldots \ldots \ldots \ldots \ldots$

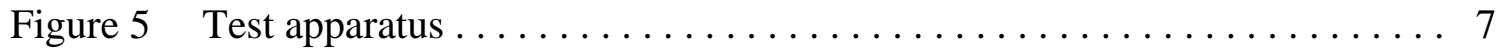

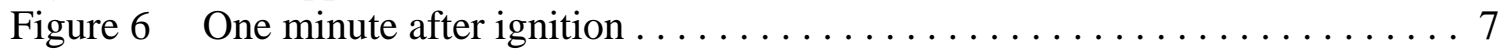

Figure 7 Thirty minutes after ignition $\ldots \ldots \ldots \ldots \ldots \ldots \ldots \ldots \ldots \ldots \ldots \ldots$

Figure 8 Example: thermocouple measurements from a normal test specimen . . . . 9 9

Figure 9 Example: thermocouple measurements from a 1/32 in. wood/plate gap

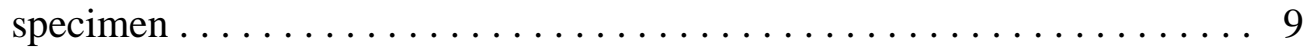

Figure 10 Example: thermocouple measurements from a 1/8 in. joint gap specimen . . 10

Figure 1110 minutes into the test the plate is still shiny $\ldots \ldots \ldots \ldots \ldots \ldots \ldots \ldots 11$

Figure 1240 minutes into the test the plate has lost its shininess $\ldots \ldots \ldots \ldots \ldots \ldots 11$

Figure 13 Post burn $-1 / 8$ in. joint gap specimen $\ldots \ldots \ldots \ldots \ldots \ldots \ldots \ldots \ldots \ldots \ldots \ldots \ldots$

Figure 14 Post burn $-1 / 32$ in. wood/plate gap specimen . . . . . . . . . . . . 12

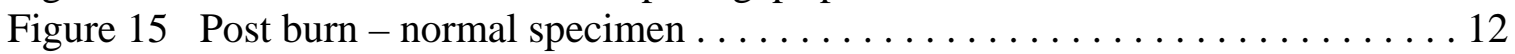

Figure 16 Char pattern on the left side of the plate $\ldots \ldots \ldots \ldots \ldots \ldots \ldots \ldots$

\section{LIST OF TABLES}

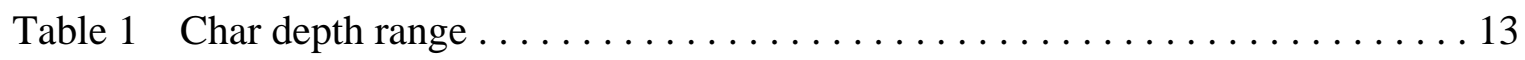




\title{
A Study of Metal Truss Plate Connectors When Exposed to Fire
}

By

Kelly A. Harman, E.I.T and James R. Lawson

\begin{abstract}
The popularity of lightweight, metal plate connected wood truss construction is increasing due to cost effectiveness, versatility, and ease of construction. This type of construction brings many concerns to the firefighting community, since structural collapse has caused numerous injuries and fatalities in the fire service. In an attempt to determine the performance of metal plate wood truss connections during fire exposures, NIST conducted a series of twelve instrumented tests exposing one side of the test specimen to the thermal exposure. Load carrying ability of the metal plate truss connections was not measured during these tests. The tests were purely an attempt to study the heat transfer between the metal plate and the wood. Results from these tests suggest that the metal plates help to protect the wood beneath the plates. However, additional work is required to produce more detailed information.
\end{abstract}

KEY WORDS: Building collapse, fire test, lightweight construction, metal plate, wood truss 


\section{INTRODUCTION}

The popularity of lightweight, metal plate connected wood truss construction is increasing due to cost effectiveness, versatility, and ease of construction. These assemblies, as seen in Figure 1, are typically constructed of two-by-four members connected with light gauge metal connectors. This construction brings many concerns to the firefighting community [1]. Many in the fire service believe that lightweight construction does not have the fire resistance that typical solid joist and rafter construction offer. Many firefighters have been injured and over 180 have lost their lives in the past twenty years due to structural collapse $[2]^{1}$.

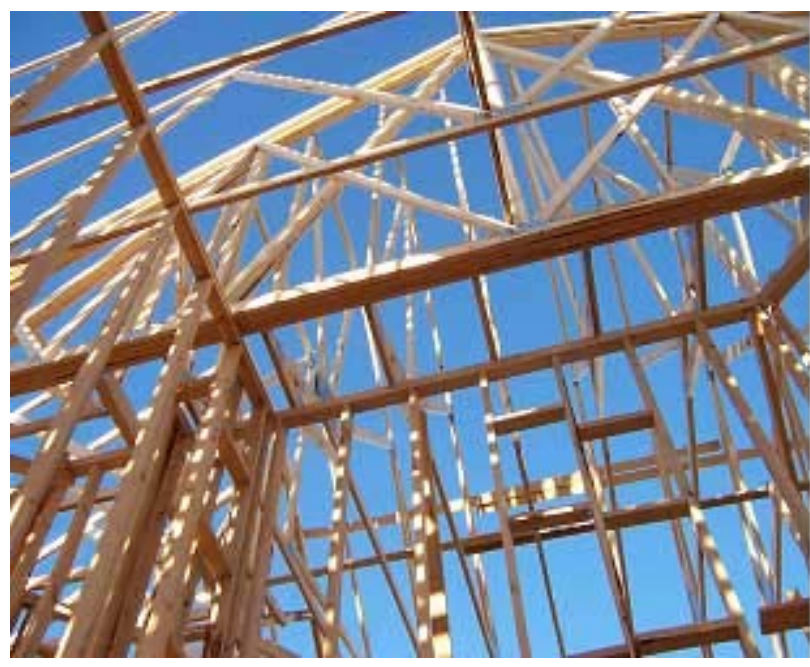

Figure 1 - Typical lightweight wood construction However, it is noted that these data do not identify the types of building construction where the injuries and deaths occurred.

The use of metal connector plates is one of the most widely discussed aspects of the lightweight wood truss. Some believe that these connectors serve as a heat sink and are weakening the wood at a faster rate while others believe that the metal plate actually reflects heat and therefore protects the wood behind the plate [3, 4]. While it is known that polished metal objects reflect heat efficiently Manny [3] questioned the reflective properties of these metal plates if they become masked by heavy smoke and soot. It is also important to note that the teeth on most truss plates only penetrate the wood about $0.38 \mathrm{in} .(9.5 \mathrm{~mm})$ and in the case of a long duration fire the wood may char beyond this

\footnotetext{
${ }^{1}$ From all causes (not including the World Trade Center).
} 
depth. While the strength of the truss construction depends on the integrity of all its parts, considerable charring causing just one connector plate to fail severely weakens the entire assembly [1].

Information on this type of connection is very limited. While conducted under different objectives, tests performed by the USDA Forest Products Laboratory gave an initial insight to metal plate behavior [5]. These results are addressed later in the discussion section of this article.

Connector plates are made of galvanized sheet steel, typically 16, 18, or 20 gauge measuring [approximately 0.062 in. (1.6 mm), 0.05 in. $(1.27 \mathrm{~mm})$, and 0.038 in. $(0.9 \mathrm{~mm})$ thick, respectively], and have teeth punched into one side. During truss fabrication truss plates are pressed into the lumber with either a hydraulic press or a roller to ensure that the teeth are fully embedded. According to ANSI/TPI 1-2002 [7], the wood members do not have to be completely flush against one another. Chapter 3, Section 3.7.6.1 allows for a wood member-to-wood member gap of 1/8 in. (3.2 mm) in roof truss assemblies. Full embedment of the metal plate teeth is also desired but not required. These tolerances will be discussed later.

In an attempt to determine whether or not the metal plate is protecting the wood beneath or further progressing its degradation and to possibly re-create the test results published by the USDA Forest Production Laboratory, twelve tests were conducted at the National Institute of Standards and Technology (NIST) Building and Fire Research Laboratory. During these tests, the strength capabilities of neither the truss plate nor the wood members were analyzed. These tests examined the heat transfer between the metal plate and the wood. 


\section{METHOD}

Sets of three different test specimens were constructed for this investigation, all using the same grade of dimension lumber. Dimension lumber is rated by its stress grade. Two by four and wider dimension lumber can be found in grades of No. 1, No. 2, No. 3, and select structural. They often appear in combinations of No. 2 and better (No. 2 \& BTR) or No. 3 \& BTR [6]. Spruce-Pine-Fir (S-P-F) lumber with a No. 2 \& BTR rating, a cross-section of $1.5 \mathrm{in.} \mathrm{(38} \mathrm{mm)} \mathrm{by} 3.5 \mathrm{in.} \mathrm{(89} \mathrm{mm),} \mathrm{from} \mathrm{here} \mathrm{on} \mathrm{referred} \mathrm{to} \mathrm{as}$ $2 \times 4$, with a moisture content of 11.5 percent, and an average density of $490 \mathrm{~kg} / \mathrm{m}^{3}$ was used. Moisture content was measured using a commercially manufactured, automated, precision, thermo-gravimetric moisture analyzer. Each specimen consisted of two 2 x 4, one ft. $(0.30 \mathrm{~m})$ long members connected by two 3 in. (76 mm) by 6 in. (152 mm) galvanized steel truss plates of 20 gauge $(0.95 \mathrm{~mm})$ with punched teeth approximately 0.31 in. $(7.9 \mathrm{~mm})$ long, one on each side. Figure 2 shows this arrangement. No load was applied to these specimens before, during, or after testing.

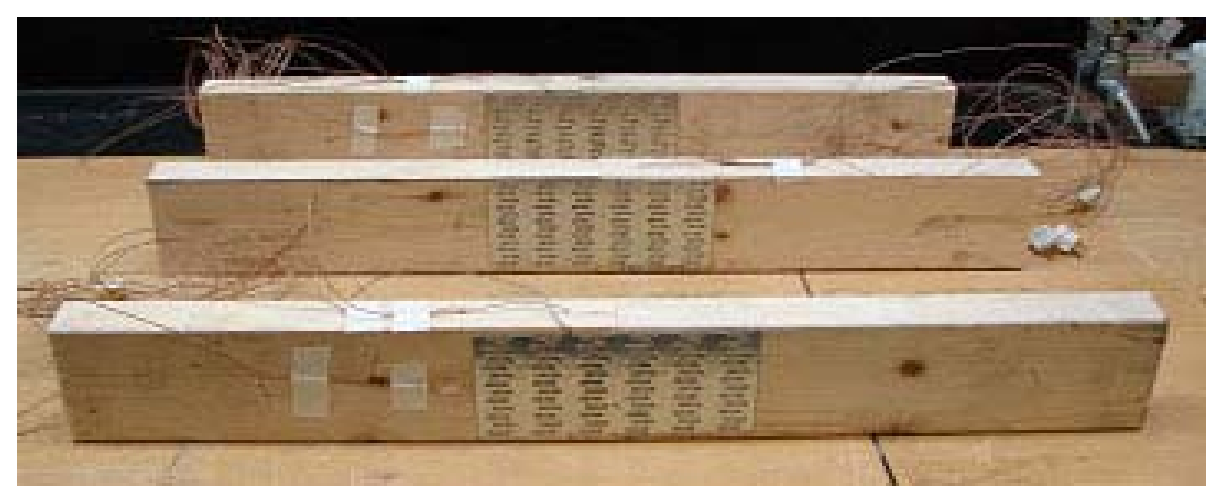

Figure 2 - Typical set up of test members

The first six test specimens were assembled with the truss plate teeth completely embedded in the pieces of wood and with no gap between the pieces of wood. These test specimens will be referred to as "normal" in the future. 
The last six test specimens consisted of three members with a 1/8 in. (3.2 mm) joint gap between the butted ends of the wood members having full plate embedment and three members with a $1 / 32 \mathrm{in}$. $(0.8 \mathrm{~mm})$ gap between the face of the metal plate and the surface of the wood to comply with the ANSI/TPI 1-2002 [7] manufacturing tolerances. Chapter 3, Section 3.7.6.1 allows a wood member-to-member joint gap of 1/8 in. $(3.2 \mathrm{~mm})$ in roof truss assemblies. It should also be noted that only a 1/16 in. (1.6 mm) gap is permitted in floor truss assemblies; this case was not tested. Section 3.7.5 allows a 1/32 in. $(0.8 \mathrm{~mm})$ gap between the wood and the metal plate. These specimens will be denoted in the future as “1/8 in. joint gap” and “1/32 in. wood/plate gap”, respectively. The exact effects on structural stability of wood charring beneath a gusset plate, where there is a gap between the metal and the wood and where plates may be improperly installed, has not been well documented [8]. A commercially manufactured flat plate hydraulic press was used for attaching the plates to ensure even embedment of the metal plate teeth. Temperatures were measured at various locations on the specimens using 0.01 in. $(0.25 \mathrm{~mm})$ diameter type K thermocouples.

The first three tests specimens were constructed with four thermocouples (A, B, C, and D). This was done in order to see if the metal plate was protecting wood adjacent to the plate on the surface. The first thermocouple, denoted "A", was placed on the surface of the wood directly behind the metal plate and was centered on the 2 x 4 's width, approximately $1.75 \mathrm{in}$. (44 mm) from the top and bottom surface edges. Thermocouple "B” was placed in the center of the 2 x 4 test specimens directly behind " $A$ ". This was accomplished by drilling a hole into the wood just larger than the thermocouple diameter. This hole was located on the center of the wood's top surface 0.75 in (19 mm) from the edge. The hole was drilled 1.75 in (44 mm) deep, and the thermocouple was inserted into the hole until it stopped at the bottom, directly behind thermocouple " $\mathrm{A}$ ”. 
Thermocouples “C” and " $\mathrm{D}$ ” were placed in a similar fashion $5 \mathrm{~mm}$ from the edge of the metal plate. Thermocouple “C” was located on the wood's surface and thermocouple "D" was inserted into the wood like "B", as described above. This arrangement can be seen in Figure 3.

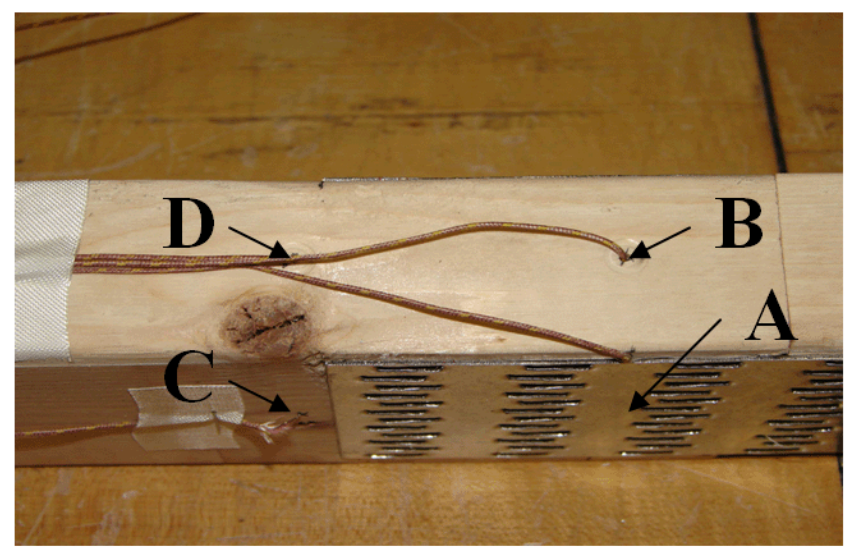

Figure 3 - Locations of thermocouples A, B, C and D

A fifth thermocouple, "E” which was used in tests four through twelve, was placed $20 \mathrm{~mm}$ from the edge of the metal plate. A close up of this configuration can be seen in Figure 4.

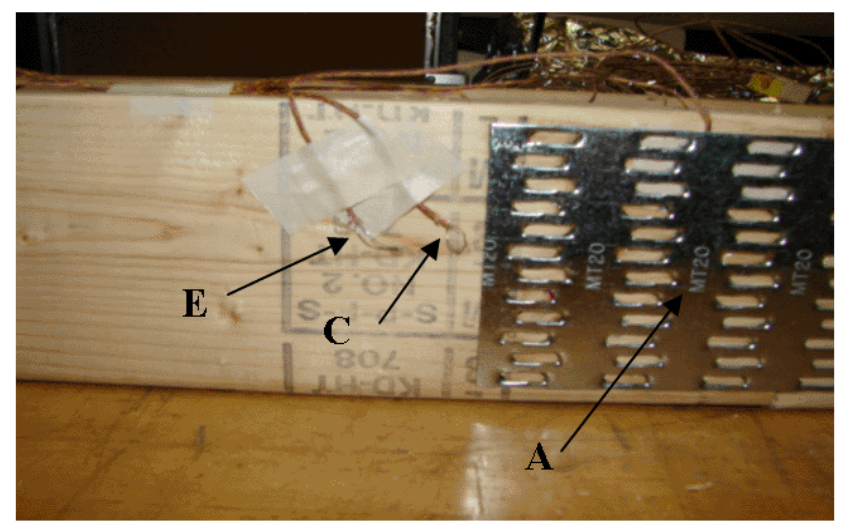

Figure 4 - Close up of surface thermocouples $C$ and $E$

The tests were conducted using a gas fired thermal radiant panel that was calibrated in order to subject the wood to a nominal constant exposure of $20 \mathrm{~kW} / \mathrm{m}^{2}$. This situation simulates initial flashover conditions during fire growth. At flashover, all 
combustible items in the room begin to burn almost simultaneously, causing a rapid increase in both heat release rates and temperatures. After flashover, the fire is often referred to as a "fully developed fire” [9]. The testing apparatus used is shown in Figure 5. The wood/metal plate

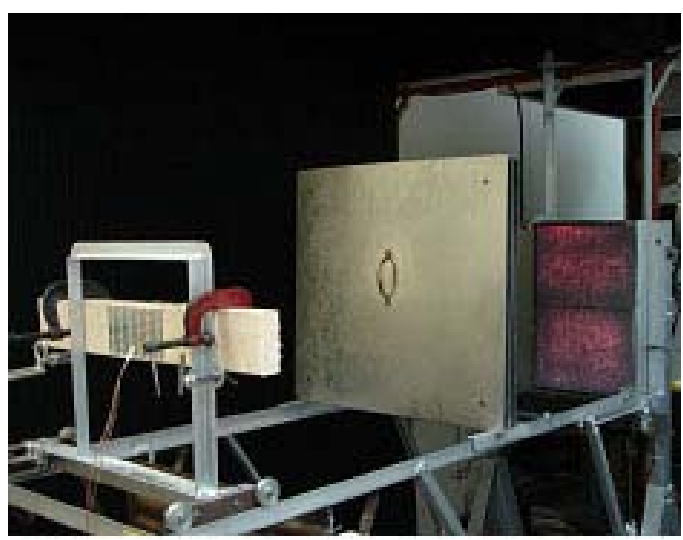

Figure 5 - Testing apparatus joint was exposed to a piloted ignition using a gas fired torch in order to introduce flame at various times during the test. The testing method at NIST applied heat and flame to one side only, the testing done by the USDA heated the sample with a furnace at a maximum temperature of $325^{\circ} \mathrm{C}$, allowing heat from all directions; a flame was never introduced [10]. The NIST testing method is illustrated in Figures 6 and 7. Tests were conducted for 60 minutes with a temperature reading taken each second using a computer controlled electronic data logger.

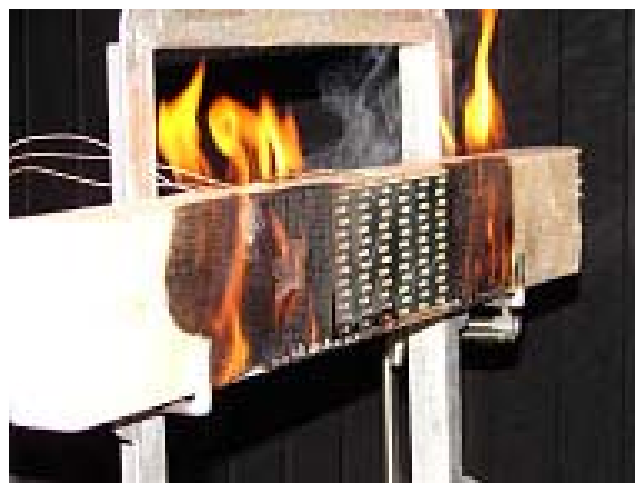

Figure 6 - One minute after ignition

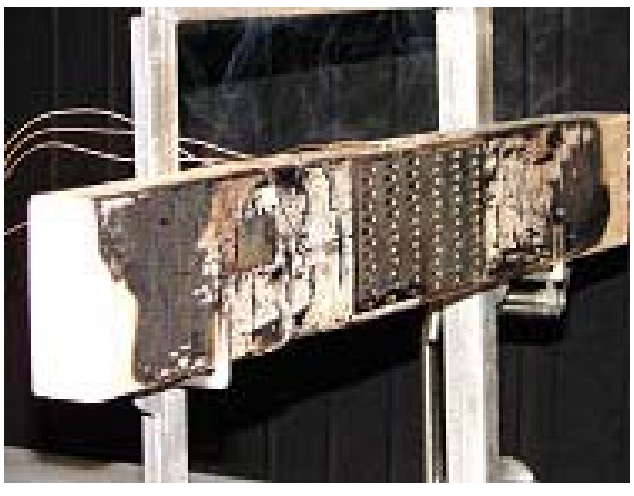

Figure 7 - Thirty minutes after ignition

\section{RESULTS AND DISCUSSION}

Results of the twelve tests were similar, indicating that the parameters that were varied plus the randomness of the tests were not significant. Figure 8 shows the 
temperatures measured by the thermocouples averaged over the six tests referred to as “normal." The sudden jump in temperatures at around $200 \mathrm{~s}$ is due to ignition of the wood. The thermocouple directly behind the metal plate, thermocouple "A", recorded lower temperatures than thermocouple "C" which was located on the surface beside the plate. This indicates that the metal plate provides some protection for the wood directly beneath it. A lower temperature was recorded in thermocouple " $\mathrm{B}$ " than at the adjacent location, thermocouple “D”. This differed from the tests conducted by the USDA. The tests conducted at NIST suggest that the metal plate is protecting the wood beneath it, whereas the USDA test results suggest that the teeth from the metal truss plate are conducting heat deeper into the wood [5]. The differences in the tests could be due to the testing method (recall that the USDA test was conducted in a furnace with the specimen exposed on all sides) as well as the temperature at which the tests were conducted. It was also found in the NIST tests that the temperature on the surface was higher at a distance of $0.79 \mathrm{in} .(20 \mathrm{~mm})$ from the edge of the plate than it was at $0.20 \mathrm{in}$. $(5 \mathrm{~mm})$ from the plate's edge. This was something not looked into in the USDA tests and is probably related to the burning behavior of the wood. 


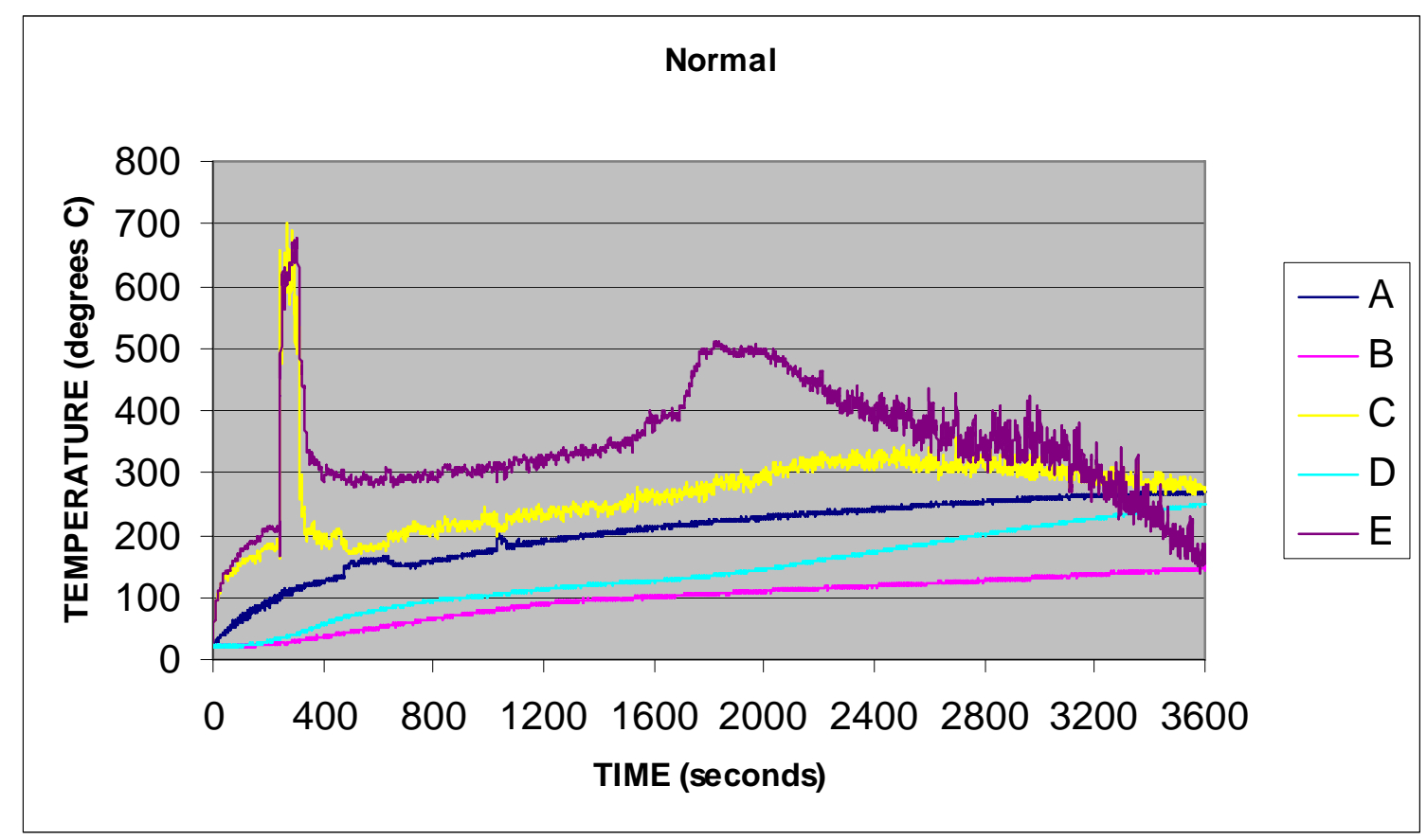

Figure 8 - Example: thermocouple measurements from a normal test specimen

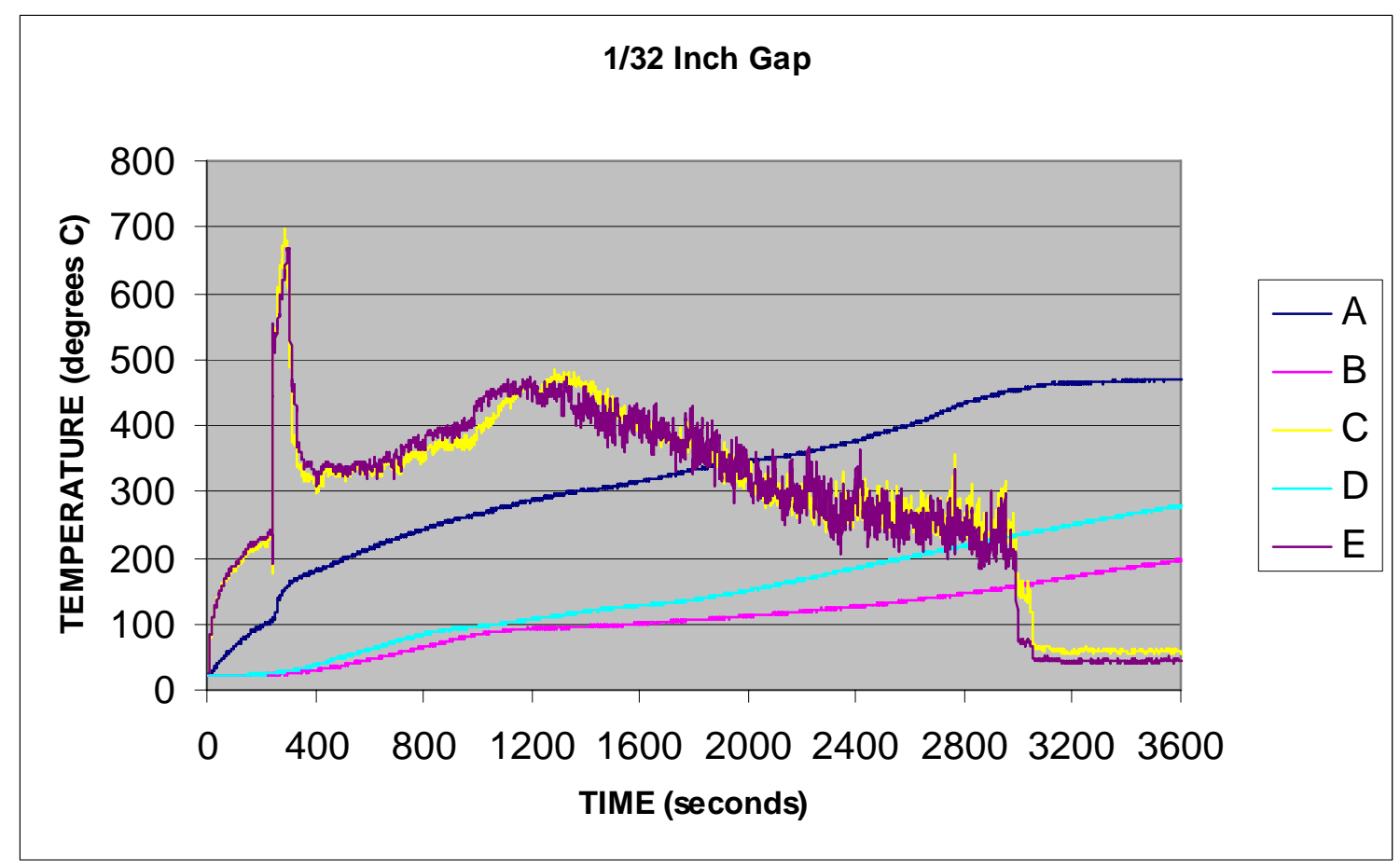

Figure 9 - Example: thermocouple measurements from a 1/32 in. wood/plate gap specimen 


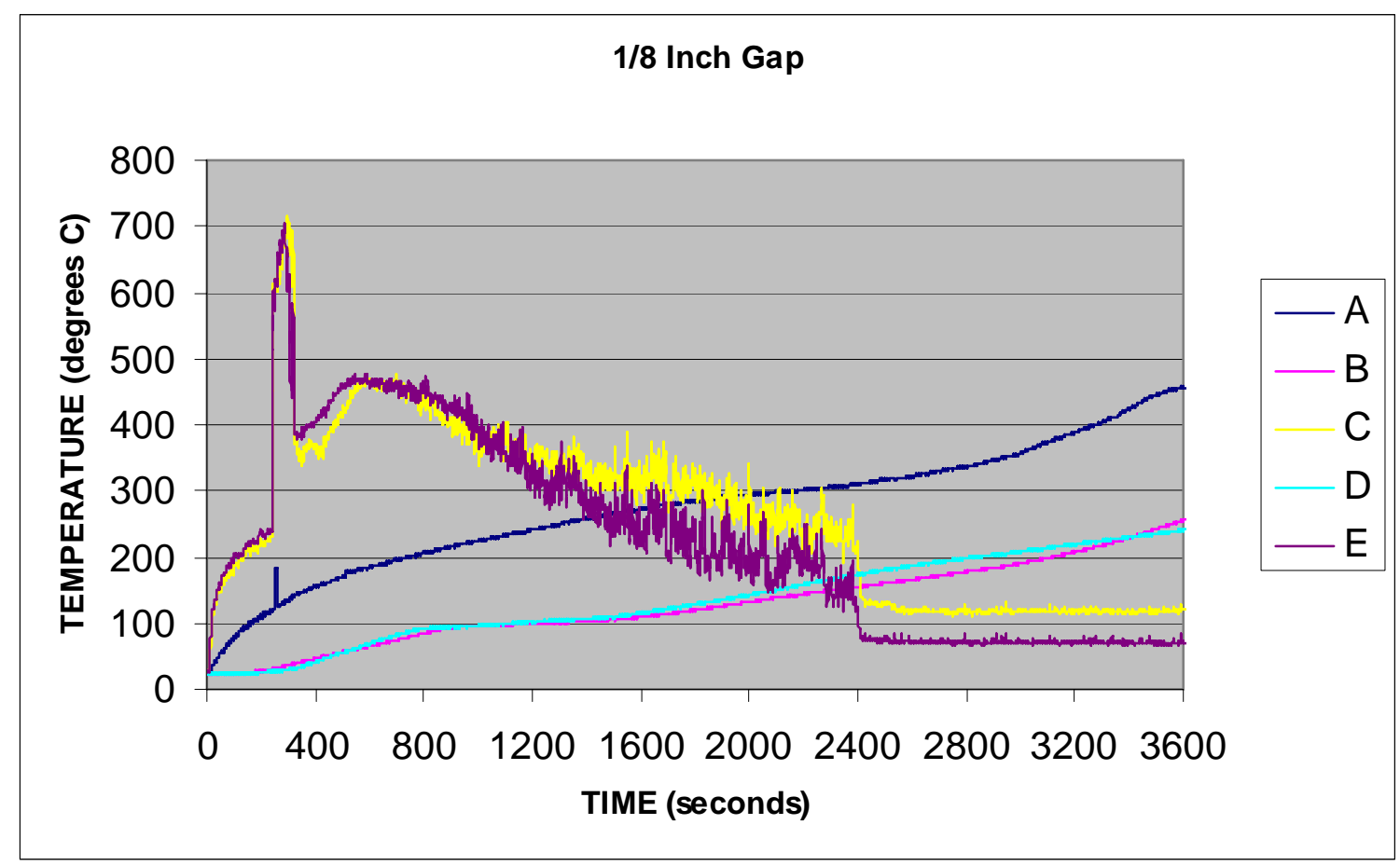

Figure 10 - Example: thermocouple measurements from a 1/8 in. joint gap specimen

(Note that thermocouples "C" and "E" lost contact with the surface at around 1700 seconds.) The highest temperature reached for an individual test during ignition and flaming, was $1007^{\circ} \mathrm{C}$ while the lowest temperature was $605^{\circ} \mathrm{C}$. These differences have to do with the variability of fire development, variations in thermocouple placement, and the uniformity of wood. Despite the fact that the wood specimens came from the same member and the testing apparatus was calibrated, each piece burned slightly different. Figures 9 and 10 show the temperatures measured (averaged over three tests each) during the 1/32 in. $(0.8 \mathrm{~mm})$ wood/plate gap tests and the 1/8 in. (3.2 $\mathrm{mm})$ joint gap tests, respectively. The gap between the plate and the wood leads to considerably higher temperatures measured behind the plate with thermocouple "A” (See Fig. 9). The joint gap also increases the temperature of thermocouple " $\mathrm{A}$ ” when compared to the normal specimen. Qualitatively speaking, the trends for the remaining thermocouples are all similar. 
Over time the metal plate, as seen in Figures 11 and 12, began to collect soot and loose its shininess. The temperature at the thermocouples behind the plate increased at a

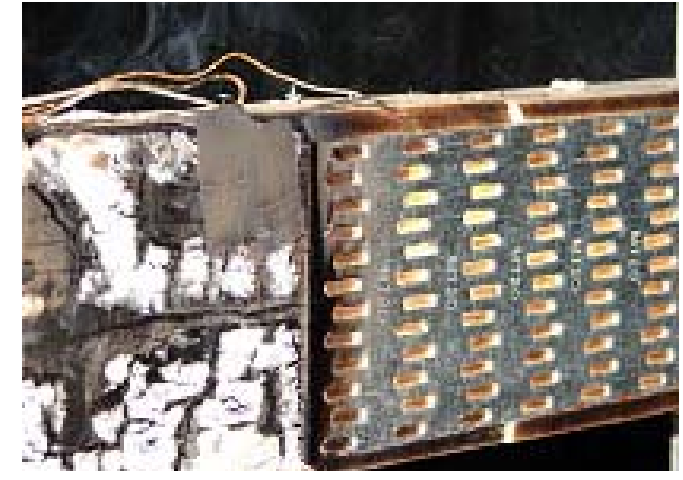

Figure 11 - 10 minutes into the test the plate is still shiny

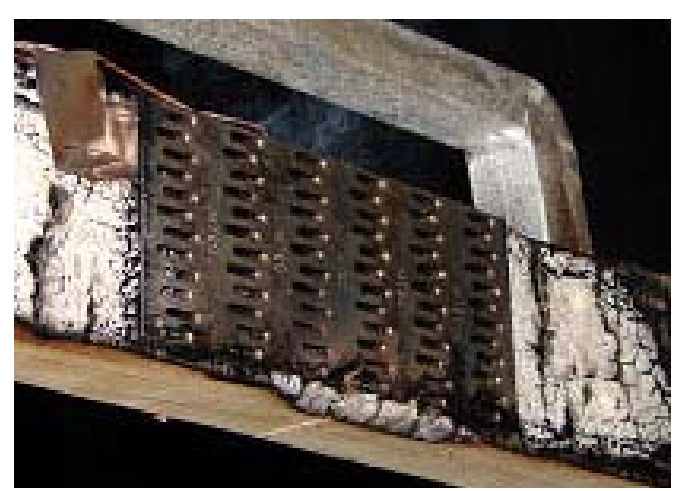

Figure 12 - 40 minutes into the test the plate has lost its shininess

constant rate. While the discoloration of the plate caused the plate to change its heat reflective properties, it is not clear how much this affected the subsequent heat transfer. One is also able see in Figure 11 how the wood beneath the plate is still its original color. Thirty minutes later in Figure 12 the plate has become quite discolored and the wood beneath the plate has also begun to char.

In each of the tests conducted thermocouple “ $A$ ” recorded lower temperatures than thermocouple “ $\mathrm{C}$ ”, and average of $215^{\circ} \mathrm{C}$ lower. This generally occurred during the first half of the test. Similar results were seen in thermocouples "B" and "D" with an average difference of $110{ }^{\circ} \mathrm{C}$. 
There were two occurrences when thermocouple " $B$ " reached a higher

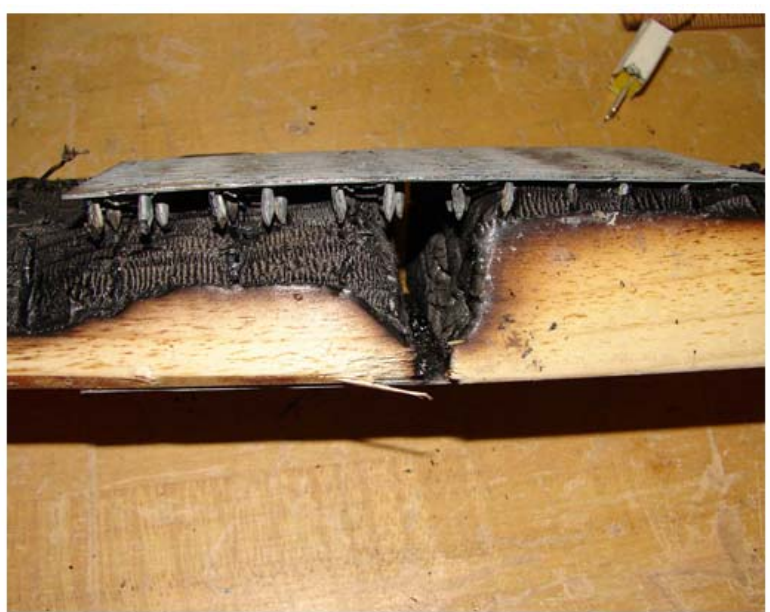

Figure 13 - Post burn - 1/8 in. joint gap specimen

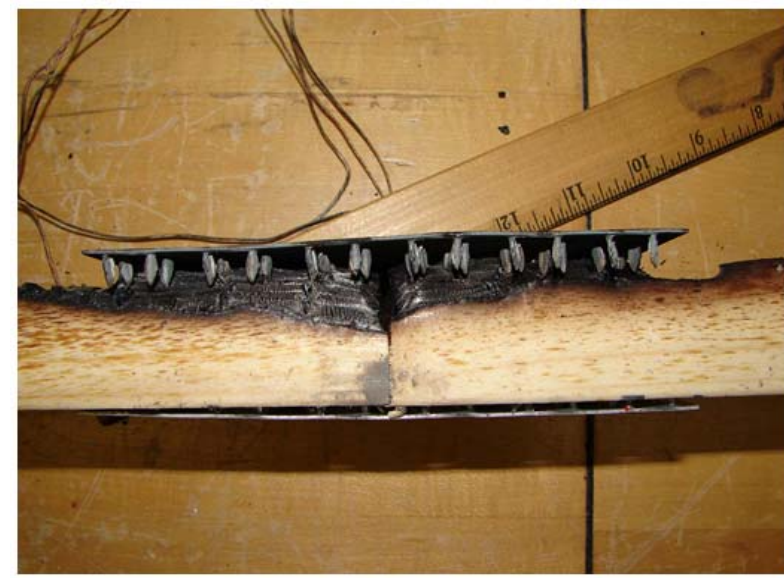

Figure 14 - Post burn - 1/32 in. wood/plate gap specimen

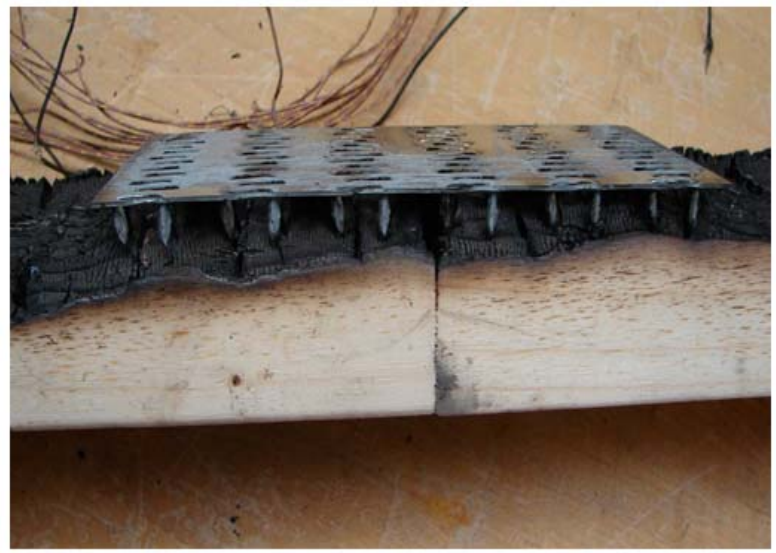

Figure 15 - Post burn - normal specimen temperature than thermocouple " $\mathrm{D}$ ".

This was in the case of the 1/8 in.

(3.2 mm) joint gap. In this arrangement

fire was able to make its way between

the wood members and char a large area

behind the metal plate. This can be seen

in Figure 13.

During the early part of the test

after ignition, thermocouple " $C$ "

recorded lower temperatures, by an

average of $45^{\circ} \mathrm{C}$, than thermocouple

“E”.

There were a few obvious differences in

the specimens with manufacturing

tolerances. The 1/8 in. (3.2 mm) joint

gap specimens recorded on average

$40{ }^{\circ} \mathrm{C}$ higher temperatures on

thermocouple " $\mathrm{B}$ " which is located in

the center of the wood behind the plate, than in the normal specimens. This was due to fire easily making its way between the two pieces of wood behind the plate. These also caused a large area 
This can be seen when comparing Figure 13 to Figure 15. On average, charring that took place in the space between butt-joint ends for the 1/8 in. (3.2 mm) joint gap specimens grew from the starting point gap of $0.15 \mathrm{in}$. $(3.8 \mathrm{~mm})$ to a width of $0.57 \mathrm{in}$. (14.5 mm), whereas little or no area burned away or charred between the normal spaced wood joint specimens. The 1/8 in. (3.2 mm) joint gap specimens recorded the greatest char depths; the 1/32 in. (3.2 mm ) wood/plate gap specimen, as seen in Figure 14, and only one of the normal specimens, Figure 15, recorded char depths great enough to completely expose the bottom row of metal teeth. The range of char depth measurements for each type of specimen is presented in Table 1. The char depth measurements were made using precision drafting tool calipers with measurements transferred to and read from a machinist scale. All char depth measurements reported (between the wood members and behind the plate) were made at locations along the edge of the metal plate. The char depth measured between the wood members was measured at the surface of the wood/metal interface and perpendicular to the wood gap or across the gap. The char depth measured behind the metal plate was measured at the surface of the wood/metal interface and perpendicular to the metal plate or in the direction of the teeth.

Table 1 - Char depth range

\begin{tabular}{|c|c|c|}
\hline Test Specimen & $\begin{array}{c}\text { Range, char depth measured } \\
\text { between wood members } \\
(\mathbf{m m})\end{array}$ & $\begin{array}{c}\text { Range, char depth measured } \\
\text { behind plate } \\
\text { (mm) }\end{array}$ \\
\hline Normal & $0-2$ & $2-26$ \\
\hline $1 / 32$ in. wood/plate gap & $3-6$ & $3-23$ \\
\hline $1 / 8$ in. joint gap & $0-15$ & $7-27$ \\
\hline
\end{tabular}


While the bottom side of each member burned in a similar fashion in the normal and 1/32 in. (3.2 mm) wood/plate specimens, fire was able to penetrate into the wood under the plate charring directly behind the plate in the case of the 1/32 in. (3.2 mm) wood/plate gap. Because of this more than just the bottom rows of teeth were exposed. Similar char patterns on the surface were seen in each specimen, each having the maximum surface char depths at a distance of 0.79 in. $(20 \mathrm{~mm})$ or greater from the edge of the metal plate on the left side and a distance of 0.55 in. $(14 \mathrm{~mm})$ or greater from the edge of the metal plate on the right side. This can be seen in Figure 16. It was noted earlier that higher temperatures were recorded at a location further from the plate than closer to the metal plate which would result in this pattern.

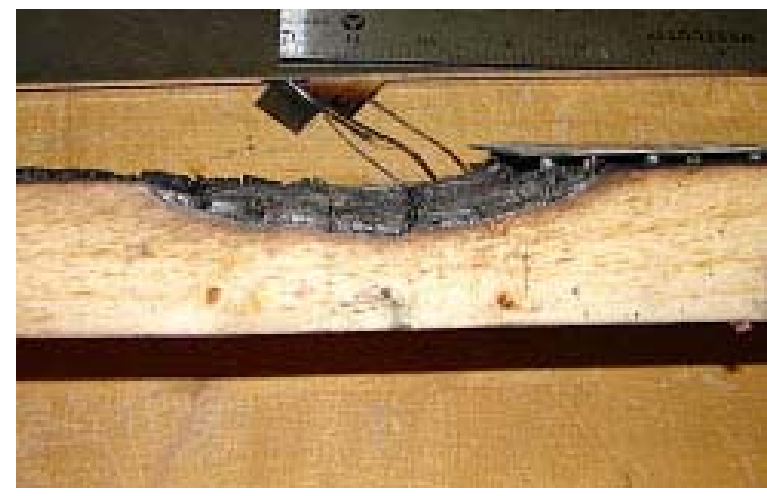

Figure 16 - Char pattern on the left side of the plate. Char depth measurement locations varied based on where flames burned the most on the wood's surface. The average surface char depth 0.75 in. $(19 \mathrm{~mm})$ was measured on average $1.54 \mathrm{in.}(39 \mathrm{~mm}$ ) from the left edge of the metal plate, and on the right edge of the metal plate an average surface char depth of $0.47 \mathrm{in.}(12 \mathrm{~mm})$ was measured on average $1.22 \mathrm{~mm}$ (31 mm) from the right edge.

\section{CONCLUSION}

From the results of these tests, it is shown that the metal plate appears to provide some level of protection for the wood beneath it as well as the wood in close proximity to the plate's edge when there is little or no gap between the plate and the wood. When burning occurred on the wood's surface behind a metal plate with a gap, teeth depth in 
the char/wood interface ranged from approximately 80 percent embedded to fully exposed.

It is important to note that these experiments were conducted with heating and fire applied to only one side of the test specimen and with no external loads applied to examine the load carrying capability of the construction system. To better understand the significance of burning around metal plates, these experiments should be repeated under various loading and fire conditions. Variations in the number and placement of thermocouples should be considered in future tests as well as variations in the orientation of the wood. The wood is expected to burn differently if aligned vertically to the radiant panel as opposed to horizontally.

With what little is known about the behavior of metal truss plate connectors when exposed to fire and with the increasing numbers of lightweight wood trusses in production, there is a need to further quantify the response of lightweight wood trusses to the impact of fire exposure.

\section{Acknowledgements:}

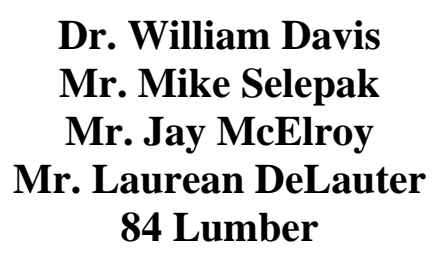

Dr. William Davis Mr. Mike Selepak

Mr. Jay McElroy 84 Lumber

\begin{tabular}{c}
\hline Dr. Steve Cramer \\
The Wood Truss Council of \\
America: \\
Kirk Grundahl \\
Ryan Dexter \\
Will Warlick \\
The Truss Plate Institute: \\
Mike Cassidy
\end{tabular}

Harman's research was performed while on appointment as a U.S. Department of Homeland Security (DHS) Fellow under the DHS Scholarship and Fellowship Program, a program administered by the Oak Ridge Institute for Science and Education (ORISE) for DHS through an interagency agreement with the U.S Department of Energy (DOE). ORISE is managed by Oak Ridge Associated Universities under DOE contract number 
DE-AC05-00OR22750. All opinions expressed in this paper are the author's and do not necessarily reflect the policies and views of DHS, DOE, or ORISE.

Note: NIST policy is to report numerically measured values in metric; however, the audience for this paper uses standard units.

\section{REFERENCES}

1. Mittendorf, John W.(1988). “Joint rafters versus lightweight wood trusses.” Fire Engineering, 141(7), 48-50.

2. Brassell, L. and Evans, D. (2003). Trends in firefighter fatalities due to structural collapse, 1979-2002. NISTIR 7069, National Institute of Standards and Technology, U.S. Department of Commerce, Gaithersburg, MD.

3. Manny, William F. (1991). "Lightweight wood trusses: More to consider.” Fire Engineering, 144(5), 62-63.

4. Meeks, John E. P.E., (2001). “Truss plate performance in fire: One person’s observations,” Structural Building Components Magazine, [online] 1 http://www.sbcmag.info/past/2001/01jun_jul/plateperformance.html. (Accessed: 23 June 2005).

5. Shrestha, D., Cramer, S., and White, R. (1995). "Simplified models for the properties of dimension lumber and metal-plate connections at elevated temperatures.” Forest Products Journal, 45(7/8), 35-42.

6. Forest Products Laboratory, Forest Service, U.S. Department of Agriculture (1999). Wood handbook: Wood as an engineering material. Forest Products Laboratory, Forest Service, USDA, Madison, WI.

7. ANSI/TPI (2002). Quality criteria for the manufacture of metal plate connected wood trusses. in: National Design Standard for Metal Plate Connected Wood Truss Construction. Truss Plate Institute, Chapter 3.

8. Malanga, Robert (1995). "Fire endurance of lightweight wood trusses in building construction.” Fire Technology, 31(1), 44-61.

9. Buchanan, Andrew H. (2001). Structural Design for Fire Safety. John Wiley \& Sons, LTD., New York.

10. White, R., Cramer, S. (1994). "Improving the Fire Endurance of Wood Truss Systems.” Pacific Timber Engineering Conference Gold Coast Australia, July 11-15. 582-589. 